\title{
Gliotoxin Inhibits Superoxide Production and Exocytosis of the Oxidant-producing Intracellular Compartments in Human Neutrophils Stimulated with Phorbol Myristate Acetate
}

\author{
Guangjun Li ${ }^{1}$, Toshihiro Kobayashi ${ }^{1}$, Shohko Tsunawaki ${ }^{2}$, Yasuhiro Ogawa ${ }^{3}$ and \\ Harumichi Seguchi ${ }^{1}$ \\ ${ }^{1}$ Department of Anatomy and Cell Biology, ${ }^{3}$ Department of Radiology, Kochi Medical School, Kochi University, Kochi, Japan and \\ ${ }^{2}$ Department of Infectious Diseases, National Research Institute for Child Health and Development, Tokyo, Japan
}

Received April 5, 2004; accepted May 6, 2004

\begin{abstract}
Fungal gliotoxin (GTX) is known to possess several potent biological effects such as immunosuppression and apoptosis. The function of this toxin, however, remains to be established. Herein we focused on the effects of GTX on the NADPH oxidase system, which includes the production of superoxide $\left(\mathrm{O}_{2}^{-}\right)$and the exocytosis of the oxidant-producing intracellular compartments (OPIC), in human neutrophils stimulated with phorbol myristate acetate (PMA). Biochemical analyses indicated that GTX inhibits both the extracellular release of $\mathrm{O}_{2}{ }^{-}$and the intracellular production of the oxidant generated upon activation of the NADPH oxidase complex, and that the toxin suppresses the up-regulation to
\end{abstract}

the cell surface of alkaline phosphatase activity which is a marker enzyme of OPIC. Fluorescence as well as enzyme cytochemical studies showed that $\mathrm{O}_{2}^{-}$is produced in intracellular compartments in PMA-stimulated cells, but not in the stimulated cells exposed to GTX. Moreover, electron microscopy revealed that GTX inhibits the association of OPIC with the plasma membrane. Taken together, the present findings confirmed that GTX inhibits the extracellular release of $\mathrm{O}_{2}{ }^{-}$and the intracellular production of the oxidant, and first demonstrate that the toxin suppresses the exocytosis of OPIC in human neutrophils stimulated with PMA.

Key words: exocytosis, gliotoxin, NADPH oxidase, neutrophils, superoxide

\section{Introduction}

Phagocytes such as neutrophils and macrophages produce superoxide $\left(\mathrm{O}_{2}^{-}\right)$through the activation of NADPH oxidase during phagocytosis and upon stimulation with a variety of agents such as phorbol myristate acetate (PMA). This enzyme comprises cytosolic (p40-phox, p47-phox, p67phox, and Rac) and membrane (cytochrome $b_{558}$ consisting of p22-phox and gp-91-phox) components. Upon stimulation, the cytosolic proteins translocate and associate with the membrane components triggering the activation of NADPH oxidase. The $\mathrm{O}_{2}{ }^{-}$formed is then converted to other reactive oxygen species (ROS) which play a crucial role in the host

Correspondence to: Toshihiro Kobayashi, Department of Anatomy and Cell Biology, Kochi Medical School, Kochi University, Kohasu, Okoh-cho, Nankoku, Kochi 783-8505, Japan.

E-mail: kobayash@med.kochi-u.ac.jp defense by microbial killing, and cause injury to surrounding tissues [7, 10, 20, 26].

Invasive aspergillosis is a serious problem in clinical practice. Patients with chronic granulomatous diseases, for example, are known to suffer recurrent infections, being unusually susceptible to Aspergillus species. The phagocytes of those patients hereditarily lack a certain component of NADPH oxidase (p22-phox, gp-91-phox, p47-phox, or p67-phox) resulting in the inability of $\mathrm{O}_{2}^{-}$production [25]. Gliotoxin (GTX) is a metabolite produced by fungi including Aspergillus fumigatus and Candida albicans found in infected tissues [1]. In human neutrophils, GTX is reported to accelerate apoptosis by the inhibition of NF-kappaB $[11,14,17,23]$, and is thought to be responsible for part of the immunosuppressive activity [24]. GTX has also been reported to inhibit the production of $\mathrm{O}_{2}^{-}$by NADPH oxidase activity [21]. The inhibitory mechanism of GTX has been clarified recently as follows: the disulfide form of GTX tar- 
gets NADPH oxidase and, as a result, the enzyme becomes inactivated [25]. These biochemical findings on the inhibitory effect of GTX on the NADPH oxidase activity were based mostly on the measurement of the amount of $\mathrm{O}_{2}^{-}$released extracellularly.

Morphological evidence using human neutrophils has demonstrated that, upon stimulation, $\mathrm{O}_{2}{ }^{-}$is produced in special intracellular organelles. These oxidant-producing intracellular compartments (OPIC) then bind directly to the plasma membrane or fuse to form larger structures that eventually become associated with the plasma membrane, and $\mathrm{O}_{2}{ }^{-}$is released extracellularly from the cells $[5,6]$. The intracellular production of $\mathrm{O}_{2}^{-}$and the extracellular release of the oxidant are thus intrinsic components of the NADPH oxidase system in human neutrophils. Therefore, it is essential to evaluate the effect of GTX on both intracellular production of $\mathrm{O}_{2}{ }^{-}$and the extracellular release of the oxidant.

We have recently developed a cytochemical method to visualize the intracellular localization and to quantify the $\mathrm{O}_{2}-$ produced intracellularly using succinimidyl ester of dichlorodihydrofluorescein diacetate $\left(\mathrm{H}_{2} \mathrm{DCFDA}\right)[9,17]$, which is not fluorescent until oxidized by reactive oxygen species [18]. In the present study, using this cytochemical method concomitantly with biochemical analyses, we confirmed that GTX inhibits both the extracellular release and the intracellular production of $\mathrm{O}_{2}^{-}$, and first demonstrated that the toxin deters the exocytosis of OPIC in human neutrophils stimulated with PMA.

\section{Materials and Methods}

\section{Reagents}

Cytochrome c, dextran (mw, 520,000), gliotoxin, Histopaque 1083, phorbol 12-myristate 13-acetate (PMA), and superoxide dismutase (SOD) were purchased from Sigma Chemical Co. (St. Louis, MO, USA). Succinimidyl ester of dichlorodihydrofluorescein diacetate ( $\mathrm{H}_{2}$ DCFDA) was obtained from Molecular Probes (Eugene, OR, USA). All other reagents were of the highest purity grade available.

\section{Cell preparation}

Human neutrophils were isolated from the peripheral blood of healthy volunteers as previously described [5]. Briefly, leukocytes were separated from erythrocytes by sedimentation in 6\% dextran with acid citrate as an anticoagulant followed by hypotonic lysis of residual erythrocytes. Cells were further enriched by centrifugation through Histopaque (cell viability was at least $98 \%$ as determined by trypan blue exclusion and $94 \%$ of them were identified as neutrophils by differential counting). Cells were maintained in phosphate-buffered saline (PBS) until use. PBS containing $1 \mathrm{mM} \mathrm{MgCl}, 1 \mathrm{mM} \mathrm{CaCl}_{2}$ and $5 \mathrm{mM}$ glucose was employed as incubation buffer solution for all the experiments unless otherwise stated.

\section{Treatment with GTX}

Cells were exposed to GTX according to the method of
Yoshida et al. [25]. Briefly, preincubation was carried out in plastic tubes with $2 \times 10^{6}$ cells in a final volume of $1 \mathrm{ml}$. Cells were prewarmed in a water bath for $5 \mathrm{~min}$ at $37^{\circ} \mathrm{C}$ before addition of GTX. GTX was then added to the cell suspension at a final concentration of $20 \mu \mathrm{M}$ followed by incubation for 30 $\min$ at $37^{\circ} \mathrm{C}$ prior to stimulation with PMA.

\section{Cell stimulation}

Human neutrophils were stimulated by treatment with PMA, a substance known to activate protein kinase C [15]. Stock solutions of PMA were prepared in DMSO and stored at $-20^{\circ} \mathrm{C}$. Cells $\left(2 \times 10^{6}\right.$ cells $\left./ \mathrm{ml}\right)$ suspended in PBS were treated with $50 \mathrm{ng} / \mathrm{ml}$ of PMA at $37^{\circ} \mathrm{C}$. PMA stock solutions were diluted with DMSO so that the final concentration of the solvent in the cell suspension was $0.25 \%$ (v/v). Unstimulated cells, which served as control, were incubated in a similar fashion, but without the addition of PMA.

\section{Measurement of extracellularly released $\mathrm{O}_{2}$}

$\mathrm{O}_{2}^{-}$released extracellularly was determined spectrophotometrically by the SOD-inhibitable reduction of cytochrome c [13]. Briefly, neutrophils in a $3 \mathrm{ml}$ cuvette were exposed to PMA and kept at $37^{\circ} \mathrm{C}$ in a thermoregulated cuvette holder. Each cuvette contained $50 \mathrm{ng} / \mathrm{ml}$ PMA, 0.1 $\mathrm{mM}$ cytochrome $\mathrm{c}$, and $1 \times 10^{6} \mathrm{cells} / \mathrm{ml}$ in PBS. The reference cuvette contained the same compounds and $60 \mu \mathrm{g} / \mathrm{ml} \mathrm{SOD.}$ Cytochrome $\mathrm{c}$ and SOD were added to the reaction mixture 1 minute prior to the addition of PMA. The extent of cytochrome c reduction was determined spectrophotometrically (Hitachi 220A spectrophotometer., Hitachi Ltd, Tokyo, Japan) by measuring the change in absorbance (A) at 550 $\mathrm{nm}$. The rate of increase in $\mathrm{A}_{550}$ was used to calculate cytochrome $\mathrm{c}$ reduction based on a specific absorbance of 21.1/mM per $\mathrm{cm}^{2}$ [12].

\section{Measurement of intracellularly produced $\mathrm{O}_{2}-$}

Cells $\left(2 \times 10^{6}\right.$ cells $\left./ \mathrm{ml}\right)$ suspended in the incubation buffer were exposed to $25 \mu \mathrm{M} \mathrm{H}_{2}$ DCFDA under constant mild agitation, for $20 \mathrm{~min}$ at $20^{\circ} \mathrm{C}$, followed by centrifugation [9]. The fluorescence intensity of the $\mathrm{H}_{2}$ DCFDA-loaded cell suspension in a $3 \mathrm{ml}$ cuvette was measured using a spectrofluorophotometer (Shimadzu RF-5300PC; Shimadzu, Kyoto, Japan) with wavelengths of excitation at $340 \mathrm{~nm}$ and emission at $510 \mathrm{~nm}$.

\section{Measurement of alkaline phosphatase activity}

Alkaline phosphatase (ALPase) activity was determined spectrophotometrically $(410 \mathrm{~nm})$ by measuring the conversion of $\mathrm{p}$-nitrophenylphosphate to p-nitrophenol. The reaction medium contained $50 \mathrm{mM}$ Tricine, $100 \mathrm{mM}$ TAPS, $2 \mathrm{mM} \mathrm{MgSO}_{4}, 5 \%$ sucrose, and $2 \mathrm{mM}$ substrate [5]. The biochemical reaction was initiated by the addition of substrate and was allowed to proceed for $15 \mathrm{~min}$ at $37^{\circ} \mathrm{C}$. After incubation, the cell suspension was centrifuged, and the resulting supernatant was used for measurement of enzyme activity. Standard curves for the product were prepared with known amounts of p-nitrophenol in the assay buffer. 


\section{Fluorescence microscopy}

The $\mathrm{H}_{2}$ DCFDA-loaded cells were placed onto a glass coverslip at the bottom of a microwell dish (35-mm dish, poly-D-lysine-coated; MatTek, Ashland, MA, USA) for 2 min at $20^{\circ} \mathrm{C}$, followed by washing in PBS. Two $\mathrm{ml}$ of prewarmed $\left(37^{\circ} \mathrm{C}\right)$ incubation buffer was then added to the dish and the latter was mounted on a thermoregulated stage of a fluorescent microscope (Axiovert S100TV; Zeiss, Jena, Germany) to ensure constant temperature at $37^{\circ} \mathrm{C}$. The microscope was equipped with a cooled CCD camera C4880 (Hamamatsu Photonics, Japan), a 100-W mercury lamp, and an appropriate set of filters. The exposure time of the CCD camera for detection of fluorescence was 0.2 sec. Fluorescence-positive intracellular compartments were visualized using Aquacosmos software (Hamamatsu Photonics, Japan) and the image was composed with Adobe Photoshop (Adobe Systems, San Jose, CA, USA).

\section{Cytochemical procedure for detection of NADPH oxidase activity}

$\mathrm{O}_{2}{ }^{-}$-producing sites were visualized using a modification of the cerium-based cytochemical method [8] of Briggs et al. [4]. Cells attached to glass coverslips were incubated in a reaction medium consisting of $20 \mathrm{mM}$ HEPES, $135 \mathrm{mM}$ $\mathrm{NaCl}, 5 \mathrm{mM} \mathrm{KCl}, 5 \mathrm{mM}$ glucose, $20 \mathrm{mM}$ Tricine, $1 \mathrm{mM}$ $\mathrm{CeCl}_{3}$, and $1 \mathrm{mM} \mathrm{NaN}$ for $10 \mathrm{~min}$ at $37^{\circ} \mathrm{C}$ followed by

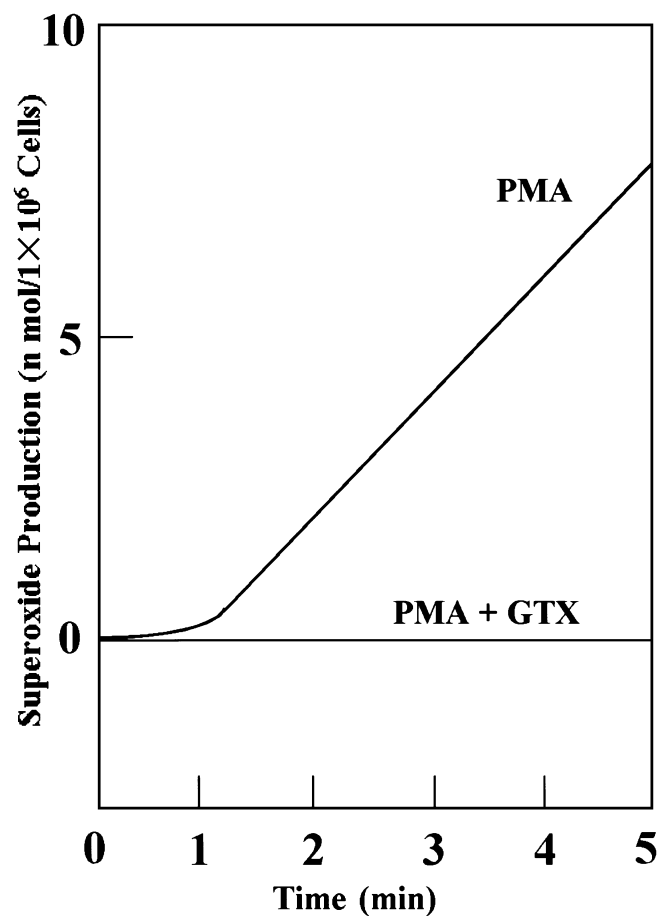

Fig. 1. Effect of GTX on the extracellular release of $\mathrm{O}_{2}^{-}$in human neutrophils stimulated with PMA. Production of $\mathrm{O}_{2}^{-}$was determined spectrophotometrically by the SOD-inhibitable reduction of cytochrome c. PMA was added to the cell suspension at the beginning of measurement. $\mathrm{O}_{2}^{-}$production is inhibited in cells exposed to GTX. Each curve is representative of four separate experiments. washing with HEPES buffer. After the cytochemical incubation, the cells were washed in HEPES buffer, and fixed with $2 \%$ glutaraldehyde in HEPES buffer for 10 min on ice.

\section{Electron microscopy}

Cells were washed with $0.1 \mathrm{M}$ cacodylate buffer $(\mathrm{pH}$ 7.4). Post-fixation was performed with $1 \%$ osmium tetroxide in cacodylate buffer for 30 minutes on ice followed by a rinse with cacodylate buffer. Cells were then dehydrated through a graded ethanol series and embedded in Spurr's epoxy resin [22]. Ultrathin sections (60 nm in thickness) were cut with a Reichert OmU4 (Reichert-Jung; Vienna, Austria), post-stained with lead citrate and uranyl acetate and observed under a JEM-100S (JEOL, Tokyo, Japan) operated at an accelerating voltage of $80 \mathrm{kV}$.

\section{Results}

\section{Extracellular release of $\mathrm{O}_{2}^{-}$}

The effect of GTX on the extracellular release of $\mathrm{O}_{2}^{-}$ produced by NADPH oxidase activity was studied in human neutrophils stimulated with PMA. NADPH oxidase activity was spectrophotometrically determined by the SOD-inhibitable reduction of cytochrome $\mathrm{c}$ which is unable to penetrate the plasma membrane. The results thus reflected the amount of $\mathrm{O}_{2}^{-}$released extracellularly. The velocity of

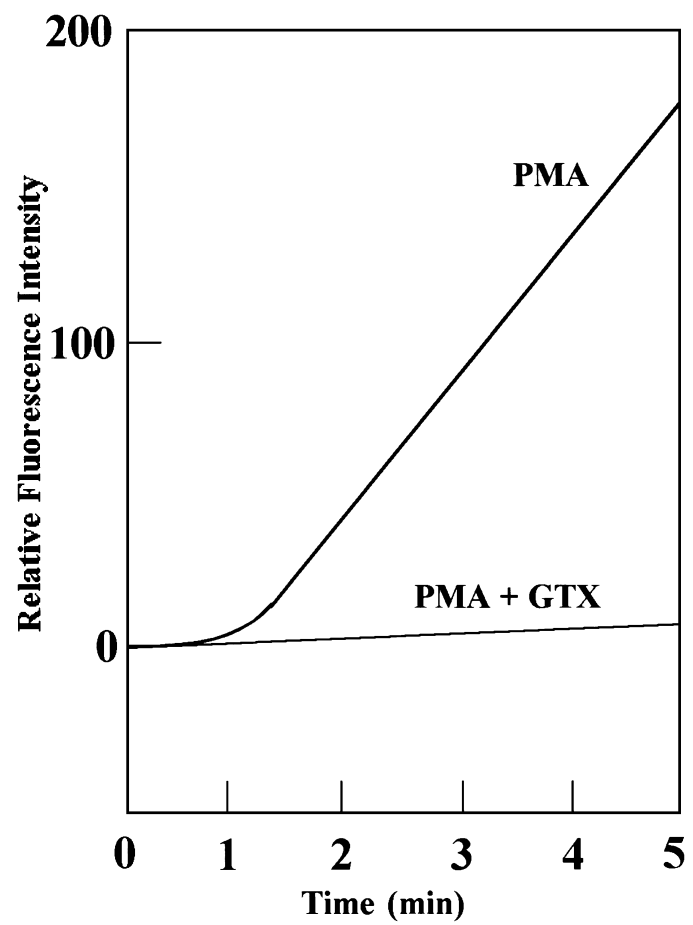

Fig. 2. Effect of GTX on the intracellular production of $\mathrm{O}_{2}^{-}$in the PMA-stimulated cells. Production of $\mathrm{O}_{2}{ }^{-}$was measured spectrofluorophotometrically in cells loaded with $\mathrm{H}_{2}$ DCFDA. PMA was added to the cell suspension at the beginning of measurement. Cells treated with GTX prior to stimulation with PMA show no increase in fluorescence. Each curve is representative of four separate experiments. 


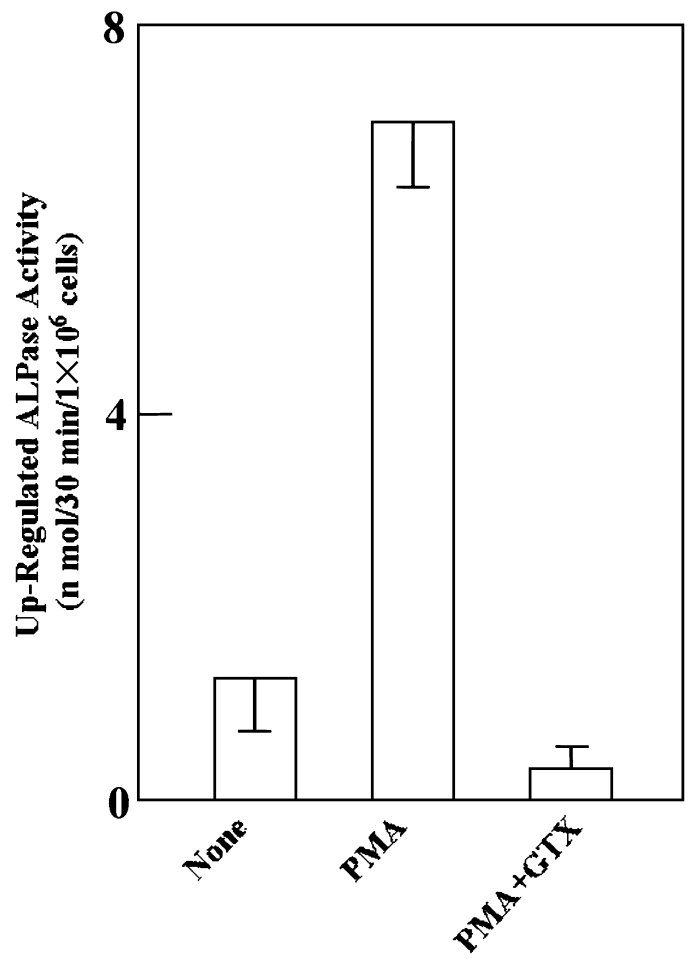

Fig. 3. Effect of GTX on the up-regulation to the cell surface of ALPase activity in human neutrophils stimulated with PMA. The up-regulation (the increase in enzyme activity detected upon incubation with or without GTX and/or PMA) is inhibited by GTX. Error bars indicate SD of four separate experiments.

extracellular release of $\mathrm{O}_{2}^{-}$was estimated as $1.9 \pm 0.4$ (n $\mathrm{mol} / \mathrm{min} / 1 \times 10^{6}$ cells) in PMA-stimulated cells. GTX completely inhibited the oxidant release in the stimulated cells (Fig. 1).

\section{Intracellular production of $\mathrm{O}_{2}^{-}$}

The intracellular production of $\mathrm{O}_{2}^{-}$was assayed spectrofluorophotometrically in cells loaded with $\mathrm{H}_{2}$ DCFDA, which is not fluorescent until oxidized by reactive oxygen species [18]. The intracellular fluorescence increased in cells stimulated with PMA and was detected within 1 min. The increase in the fluorescence emitted by the NADPH oxidase activity was estimated as $46.8 \pm 7.8$ (relative fluorescence intensity/min) in PMA-stimulated cells. GTX strongly inhibited the intracellular production of the oxidant in the stimulated cells (95\% inhibition) (Fig. 2).

\section{Up-regulation of alkaline phosphatase (ALPase) activity}

The up-regulation to the cell surface of ALPase activity, which is a marker of OPIC [5], was spectrophotometrically assayed to determine the degree of association of OPIC with the plasma membrane. Since the substrate, p-nitrophenylphosphate, does not readily penetrate the plasma membrane, the resulting ALPase activity represents the enzyme facing the extracellular space at the cell surface [5]. The amount of up-regulated ALPase activity (the increase in enzyme activity detected upon incubation with or without
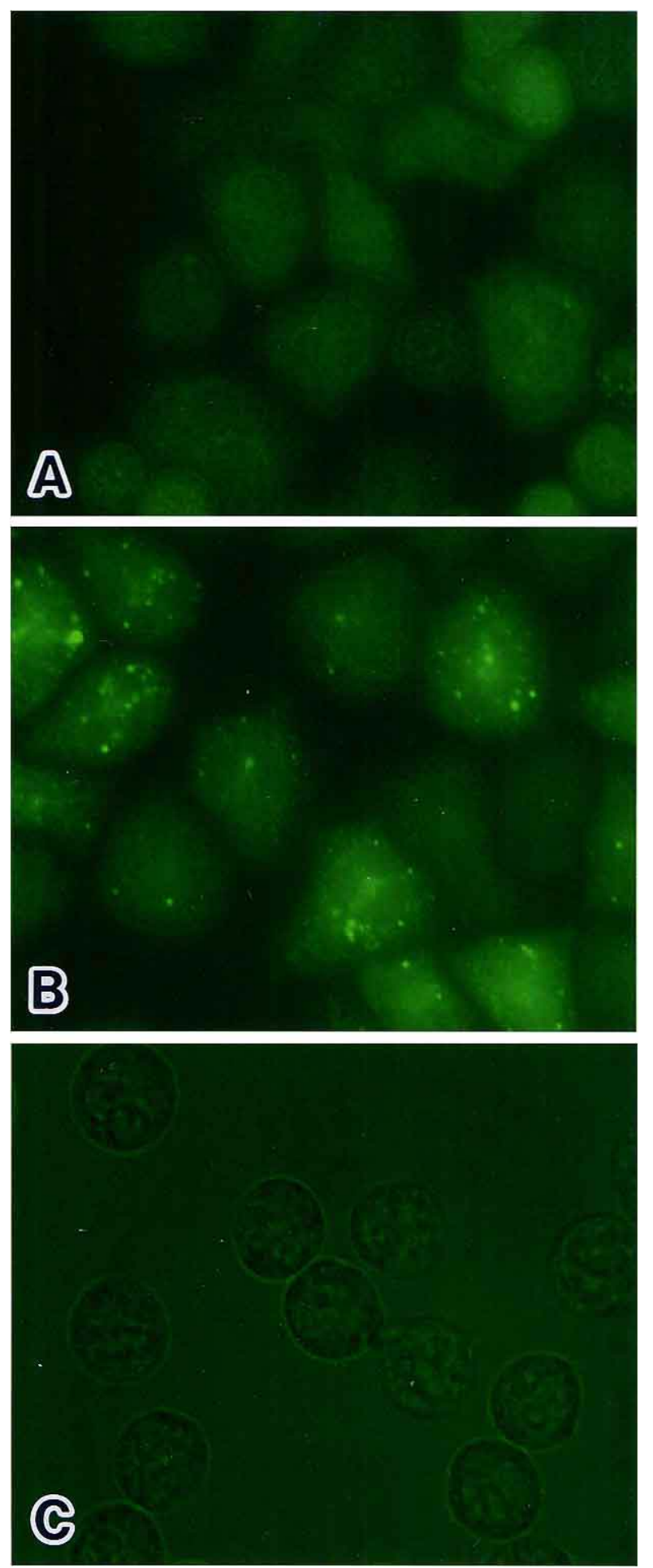

Fig. 4. Fluorescence micrographs showing $\mathrm{O}_{2}{ }^{-}$-producing sites in human neutrophils. The $\mathrm{H}_{2}$ DCFDA-loaded cells were stimulated with (B) or without PMA (A) for $5 \mathrm{~min}$, or exposed to GTX for 30 min followed by stimulation with PMA for $5 \mathrm{~min}(\mathbf{C})$ at $37^{\circ} \mathrm{C}$. Specific fluorescence labeling of NADPH oxidase activity is observed in intracellular compartments in cells treated with PMA only, but not in unstimulated or PMA-stimulated cells exposed to GTX. 

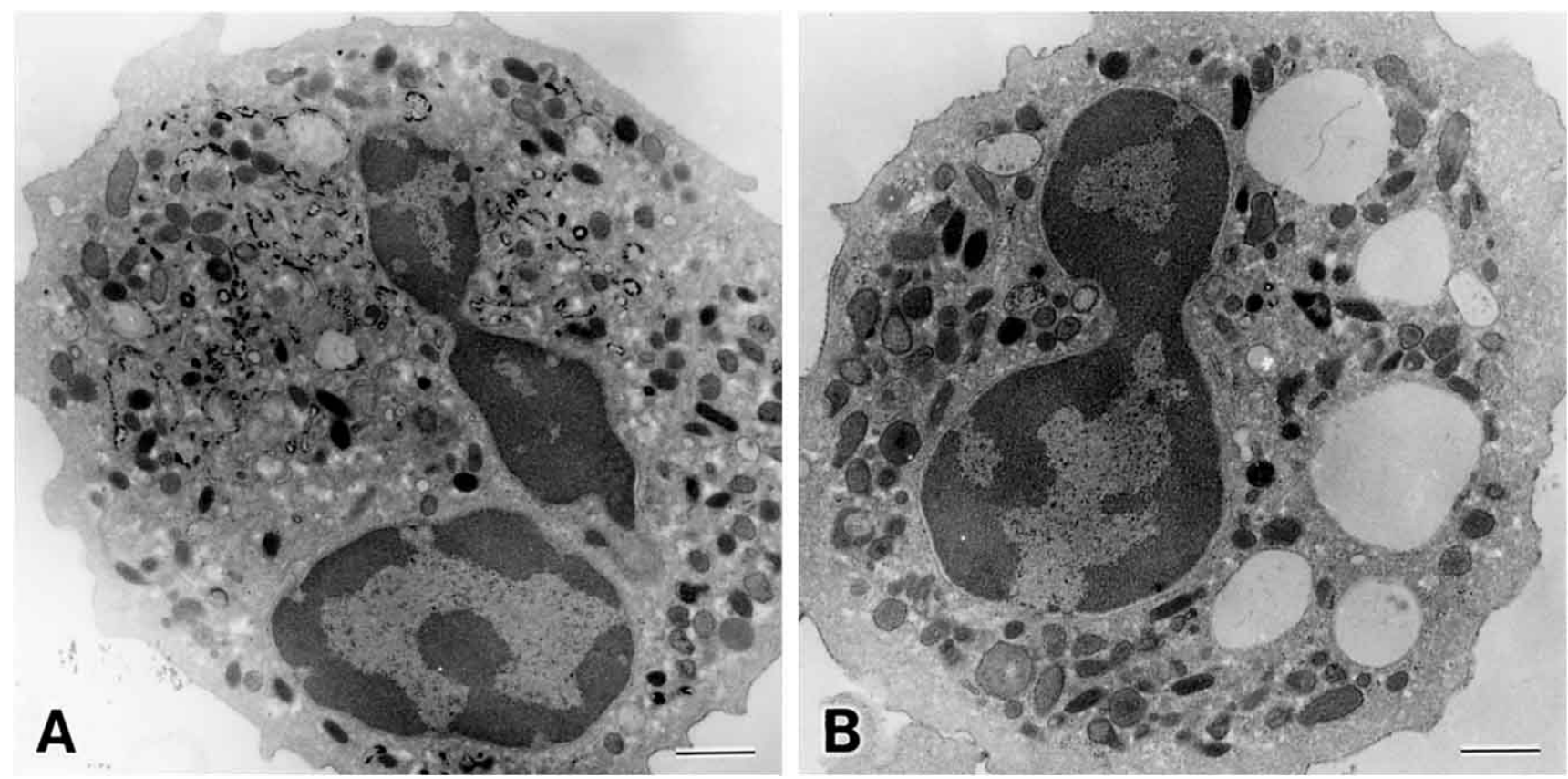

Fig. 5. Electron micrographs showing $\mathrm{O}_{2}^{-}$-producing sites in neutrophils stimulated with PMA (A), and in those loaded with GTX followed by stimulation with PMA (B). The reaction product of the NADPH oxidase activity was localized in intracellular compartments of variable sizes. GTX inhibits the production of reaction deposits. Bar=1 $\mu \mathrm{m}$.

GTX and/or PMA) in cells incubated without GTX and PMA, in PMA-stimulated cells, and in GTX-loaded cells followed by stimulation with PMA, was estimated as $1.2 \pm 0.5,6.9 \pm 0.6$, and $0.3 \pm 0.2\left(\mathrm{n} \mathrm{mol} / 30 \mathrm{~min} \pm \mathrm{SD} / 1 \times 10^{6}\right.$ cells), respectively (Fig. 3). The results showed a clear GTX-induced inhibition on the up-regulation of OPIC (95.7\% inhibition).

\section{Localization of $\mathrm{O}_{2}^{-}$-producing sites by fluorescence microscopy}

The effect of GTX on intracellular $\mathrm{O}_{2}^{-}$production by NADPH oxidase activity was evaluated in $\mathrm{H}_{2}$ DCFDA-loaded cells using fluorescence microscopy (Fig. 4). Fluorescence was detected in spherical intracellular compartments of different sizes (Fig. 4B). No specific labeling for NADPH oxidase activity was seen either in unstimulated cells (Fig. 4A) or in PMA-stimulated cells exposed to GTX (Fig. 4C). Morphologically, the GTX-loaded cells showed no spreading on the glass coverslips coated with poly-D-lysine as was the case in unstimulated or PMA-stimulated cells. This finding suggests that GTX disrupts the normal organization of the cytoskeleton resulting in the suppression of the formation of pseudopodia and lamellipodia.

\section{Localization of the $\mathrm{O}_{2}^{-}$-producing sites by electron microscopy}

The localization of NADPH oxidase activity was also studied using the cerium-based enzyme cytochemical method. The reaction product of the enzyme activity was detected in intracellular compartments of different sizes in PMA-stimulated cells (Fig. 5A). GTX inhibited the production of reaction deposits (Fig. 5B). In controls, no reac- tion product was observed either in unstimulated cells or in PMA-stimulated cells exposed to $2 \mathrm{mM}$ p-benzoquinone, a scavenger of $\mathrm{O}_{2}^{-}$(data not shown).

\section{Quantification of OPIC association with the plasma membrane}

The effect of GTX on the association of OPIC with the plasma membrane was assayed by calculating the number of OPIC fused to the plasma membrane, under an electron microscope, in cells incubated in the cytochemical reaction medium for the detection of ALPase activity [13]. As shown in Table 1, the number of plasma membraneassociated structures was $58 \pm 11$ and $2 \pm 1$ (number $\pm \mathrm{SD} / 1 \times$ $10^{3}$ cells) in PMA-stimulated cells and in the stimulated cells exposed to GTX, respectively. The results clearly indicate that GTX inhibits the association of OPIC with the plasma membrane (96.6\% inhibition).

Table 1. Effect of GTX on the exocytosis of $\mathrm{O}_{2}^{-}$-producing intracellular compartments in human neutrophils

\begin{tabular}{lcc}
\hline Treatment & Count $/ 10^{3}$ & Cells (\%) \\
\hline PMA & $58 \pm 11$ & 100 \\
PMA+GTX & $2 \pm 1$ & 3.4 \\
\hline
\end{tabular}

Cells were stimulated with PMA for $5 \mathrm{~min}$ at $37^{\circ} \mathrm{C}$. GTX inhibits the association of these organelles with the plasma membrane. Data shown here are the mean $\pm \mathrm{SD}$ of oxidant-producing structures associated with the plasma membrane per $10^{3}$ cells. 


\section{Discussion}

The inhibitory effect of GTX on NADPH oxidase system, which includes the production of $\mathrm{O}_{2}{ }^{-}$and the exocytosis of OPIC, were herein elucidated using PMA-stimulated neutrophils isolated from healthy human peripheral blood.

It has been recently demonstrated that the disulfide form of GTX targets NADPH oxidase followed by the inactivation of the enzyme [25]. However, the results of this biochemical analysis are based on the inhibitory effect of GTX on extracellular release of $\mathrm{O}_{2}^{-}$. In the present biochemical study, we confirmed that GTX inhibits the extracellular release of $\mathrm{O}_{2}^{-}$, and further clarified that the toxin suppresses the intracellular production of the oxidant by NADPH oxidase activity upon stimulation with PMA. In a separate experiment, we have previously demonstrated that ML-7, (5-iodonaphthalene-1-sulfonyl) homopiperazine, a potent myosin light chain kinase inhibitor, has a different effect on the $\mathrm{O}_{2}^{-}$producing system in a myosin light chain kinaseindependent manner which results in the inhibition of the extracellular release of $\mathrm{O}_{2}^{-}$, but not the intracellular production of the oxidant in human neutrophils stimulated with PMA [16]. Both GTX and ML-7 are, therefore, considered to be useful tools for analyzing the dynamics of $\mathrm{O}_{2}^{-}$production by NADPH oxidase activity.

In the present morphological study, we employed a cytochemical approach previously developed in our laboratory to detect $\mathrm{O}_{2}{ }^{-}$-producing intracellular compartments in human living neutrophils stimulated with PMA by fluorescence microscopy [9]. The reliability of this method was confirmed by the comparison of neutrophils isolated from normal human peripheral blood with those obtained from patients with chronic granulomatous disease lacking gp91phox, which are not able to produce $\mathrm{O}_{2}^{-}$[19]. The specific fluorescence caused by NADPH oxidase activity was observed in intracellular compartments of different sizes in the stimulated cells. Fluorescence was not visualized, however, in the stimulated cells exposed to GTX. In addition, the electron microscopical analysis revealed that the toxin inhibits the formation of the reaction product of the NADPH oxidase activity in the stimulated cells. These findings confirm that the toxin inhibits the intracellular production of $\mathrm{O}_{2}^{-}$in the stimulated cells.

Human neutrophils contain several kinds of intracellular granules: azurophil granules, specific granules, gelatinase granules, and secretory vesicles [3]. It has been reported that GTX inhibits the release of lactoferrin contained in the specific granules [21]. In the present study, we first demonstrated that GTX inhibits the release of OPIC, that is, the secretory vesicles of Borregaard and Cowland [3]. This is confirmed by the fact that GTX inhibits the up-regulation of ALPase activity, and that the association of OPIC to the plasma membrane is inhibited in the presence of GTX. GTX has further been reported to diminish phagocytosis and chemotaxis in human neutrophils [21]. It is worth noting that OPIC contains several biologically significant molecules such as Fc $\gamma$-receptor III and a receptor for chemotactic factor, formylmethionyl-leucyl-phenylalanine [2]. It is thus suggested that the inhibition of phagocytosis and chemotaxis by GTX is partly caused by the suppression of the association of OPIC with the plasma membrane.

In conclusion, the evidence at hand indicates that GTX inhibits both the $\mathrm{O}_{2}^{-}$production by NADPH oxidase activity and the association of OPIC with the plasma membrane. The latter, in turn, is considered to induce subsequent inhibition of phagocytosis and chemotaxis in human neutrophils. The fungus producing GTX is thus suggested to escape the attack of the neutrophils through this inhibitory pathway.

\section{Acknowledgment}

We thank Ms Eva Garcia del Saz (Kochi Medical School) for her careful reading of the manuscript.

\section{References}

1. Bauer, J., Gareis, M., Bott, A. and Gedek, B. (1989) Isolation of a mycotoxin (gliotoxin) from a bovine udder infected with Aspergillus fumigatus. J. Med. Vet. Mycol. 27; 45-50.

2. Borregaard, N., Lolloke, K., Kjeldsen, L., Sengeløv, H., Bastholm, L., Nielsen, M. H. and Bainton, D. F. (1993) Human neutrophil granules and secretory vesicles. Eur. J. Haematol. 51; 187-198.

3. Borregaard, N. and Cowland, J. B. (1997) Granules of the human neutrophilic polymorphonuclear leukocytes. Blood 89; 35033521.

4. Briggs, R. T., Drath, D. B., Karnovsky, M. L. and Karnovsky, M. J. (1975) Localization of NADH oxidase on the surface of human polymorphonuclear leukocytes by a new cytochemical method. J. Cell Biol. 67; 566-586.

5. Kobayashi, T. and Robinson, J. M. (1991) A novel intracellular compartment with unusual secretory properties in human neutrophils. J. Cell Biol. 113; 743-756.

6. Kobayashi, T., Robinson, J. M. and Seguchi, H. (1998) Identification of intracellular sites of superoxide production in stimulated neutrophils. J. Cell Sci. 111; 81-91.

7. Kobayashi, T. and Seguchi, H. (1999) Novel insight into current models of NADPH oxidase regulation, assembly and localization in human polymorphonuclear leukocytes. Histol. Histopathol. 14; 1295-1308.

8. Kobayashi, T., Garcia del Saz, E., Hendry, J. and Seguchi, H. (1999) Detection of oxidant producing-sites in glutaraldehydefixed human neutrophils and eosinophils stimulated with phorbol myristate acetate. Histochem. J. 31: 181-194.

9. Kobayashi, T., Zinchuk, V. S., Okada, T., Wakiguchi, H., Kurashige, T., Takatsuji, H. and Seguchi, H. (2000) A simple approach for the analysis of intracellular movement of oxidantproducing intracellular compartments in living neutrophils. Histochem. Cell Biol. 113; 251-257.

10. Kobayashi, T., Tsunawaki, S. and Seguchi, H. (2001) Evaluation of the process for superoxide production by NADPH oxidase in human neutrophils: evidence for cytoplasmic origin of superoxide. Redox Rep. 6; 27-36.

11. Liu, Y., Zhang, J., Zhao, Z. and Ling, Y. (2003) Pro-apoptotic role of NF-kappaB pathway inhibition in lipopolysaccharidestimulated polymorphonuclear neutrophils. Chin. Med. J. 116; $1257-1261$.

12. Massey, V. (1959) The microestimation of succinate and the extinction coefficient of cytochrome c. Biochim. Biophys. Acta 34; $255-256$. 
13. McCord, J. M. and Fridovich, I. (1969) Superoxide dismutase. An enzymic function for erythrocuprein (hemocuprein). J. Biol. Chem. 244; 6049-6055.

14. Moulding, D. A., Akgul, C., Derouet, M., White, M. R. and Edwards, S. W. (2001) BCL-2 family expression in human neutrophils during delayed and accelerated apoptosis. J. Leukoc. Biol. 70; 783-792.

15. Nishizuka, Y. (1986) Studies and perspectives of protein kinase C. Science 233; 305-312.

16. Odani, K., Kobayashi, T., Ogawa, Y., Yoshida, S. and Seguchi, H. (2003) ML-7 inhibits exocytosis of superoxide-producing intracellular compartments in human neutrophils stimulated with phorbol myristate acetate in a myosin light chain kinase-independent manner. Histochem. Cell Biol. 119; 363-370.

17. Renshaw, S. A., Parmar, J. S., Singleton, V., Rowe, S. J., Dockrell, D. H., Dower, S. K., Bingle, C. D., Chilvers, E. R. and Whyte, M. K. (2003) Acceleration of human neutrophils apoptosis by TRAIL. J. Immunol. 170; 1027-1033.

18. Robinson, J. P., Bruner, L. H., Bassoe, C. F., Hudson, J. L., Ward, P. A. and Phan, S. H. (1988) Measurement of intracellular fluorescence of human monocytes relative to oxidative metabolism. J. Leukoc. Biol. 43; 304-310.

19. Roos, D., de Boer, M., Kuribayashi, F., Meischl, C., Weening, R. S., Segal, A. W., Ahlin, A., Nemet, K., Hossle, J. P., Bernatowska-Matuszkiewicz, E. and Middleton-Price, H. (1996) Mutations in the X-linked and autosomal recessive forms of chronic granulomatous disease. Blood 87; 1663-1681.

20. Seguchi, H. and Kobayashi, T. (2001) Cytochemistry of NADPH oxidase activity in human neutrophils. Acta Histochem. Cytochem. 34; 85-89.

21. Shah, D. T., Jackman, S., Engle, J. and Larsen, B. (1998) Effect of gliotoxin on human polymorphonuclear neutrophils. Infect. Dis. Obstet. Gynecol. 6; 168-175.

22. Spurr, A. R. (1969) A low-viscosity epoxy resin embedding medium for electron microscopy. J. Ultrastruct. Res. 26; 31-43.

23. Ward, C., Chilvers, E. R., Lawson, M. F., Pryde, J. G., Fujihara, S., Farrow, S. N., Haslett, C. and Rossi, A. G. (1999) NF-kappaB activation is a critical regulator of human granulocyte apoptosis in vitro. J. Biol. Chem. 274; 4309-4318.

24. Watanabe, A., Kamei, K., Sekine, T., Waku, M., Nishimura, K., Miyaji, M. and Kuriyama, T. (2003) Immunosuppressive substances in Aspergillus fumigatus culture filtrate. J. Infect. Chemother. 9; 114-121.

25. Yoshida, L. S., Abe, S. and Tsunawaki, S. (2000) Fungal gliotoxin targets the onset of superoxide-generating NADPH oxidase of human neutrophils. Biochem. Biophys. Res. Commun. 268; 716-723.

26. Yoshida, L. S., Nishida, S., Shimoyama, T., Kawahara, T., Kondo-Teshima, S., Rokutan, K., Kobayashi, T. and Tsunawaki, S. (2004) Superoxide generation by Nox1 in guinea pig gastric mucosal cells involves a component with p67phox-ability. Biol. Pharm. Bull. 27; 147-155. 